\title{
BMJ A cross-sectional study of workplace open social capital and blood pressure: a multilevel analysis at Japanese manufacturing companies
}

\author{
Yoshihisa Fujino, ${ }^{1}$ Tatsuhiko Kubo, ${ }^{1}$ Masamizu Kunimoto, ${ }^{2}$ Hidetoshi Tabata, ${ }^{2}$ \\ Takuto Tsuchiya, ${ }^{2}$ Koji Kadowaki, ${ }^{2}$ Takehiro Nakamura, ${ }^{3}$ Ichiro Oyama ${ }^{4}$
}

To cite: Fujino $\mathrm{Y}$, Kubo T, Kunimoto M, et al. A crosssectional study of workplace social capital and blood pressure: a multilevel analysis at Japanese manufacturing companies. BMJ Open 2013;3:e002215

doi:10.1136/bmjopen-2012002215

- Prepublication history for this paper are available online. To view these files please visit the journal online (http://dx.doi.org/10.1136/ bmjopen-2012-002215).

Received 12 October 2012 Accepted 11 January 2013

This final article is available for use under the terms of the Creative Commons Attribution Non-Commercial 2.0 Licence; see http://bmjopen.bmj.com

For numbered affiliations see end of article.

Correspondence to Dr Yoshihisa Fujino; zenq@ med.uoeh-u.ac.jp

\section{ABSTRACT}

Objectives: We examined the contextual effect of workplace social capital on systolic blood pressure (SBP).

Design: Cross-sectional.

Setting: A conglomerate from 58 workplaces in Japan.

Participants: Of the 5844 workers at a Japanese conglomerate from 58 workplaces, 5368 were recruited. Individuals who received drugs for hypertension $(n=531)$ and who lacked information on any variable $(n=167)$ were excluded from the analyses, leaving 4735 individuals (3281 men and 1454 women) for inclusion.

\section{Primary and secondary outcome measures:} Systolic blood pressure.

Results: The contextual effect of workplace social capital on SBP was examined using a multilevel regression analysis with a random intercept. Coworker support had a contextual effect at the workplace level (coefficient $=-1.97, p=0.043$ ), while a lack of trust for coworkers (coefficient $=0.27, p=0.039$ ) and lack of helpfulness from coworkers were associated with SBP (coefficient $=0.28, p=0.002$ ).

Conclusions: The present study suggested that social capital at the workplace level has beneficial effects on SBP.

\section{INTRODUCTION}

Psychosocial stressors in the workplace and their impact on health are now an important issue with regard to not only public health but also business management. The dominant theory in job stress studies is the demand-control-support model, in which stress is thought to result from a mixture of high demands, low control and low social support. ${ }^{1}{ }^{2}$ Recent studies in this field have attempted to combine the demand-controlsupport model with other theoretical models, such as the effort-reward imbalance

\section{ARTICLE SUMMARY}

Article focus

- The workplace represents an important social unit. It is a significant source of social capital.

- While an association between social capital and hypertension has been suggested by studies in a neighbourhood context, only a study from the Finnish Public Sector Study reported their association in an occupational setting.

- The present study examined the association between workplace social capital at the workplace level and systolic blood pressure (SBP) with consideration to individual factors based on the job-demand-control model.

Key messages

- The present study found that coworker support at the workplace level was associated with SBP.

- The present study may provide suitable evidence to encourage workplace-level improvement activities since every worker in a workplace with higher social capital may receive a beneficial effect on health.

Strengths and limitations of this study

- The main strength of this study is that it examined the workplace social capital among workers in Japan where working behaviour and culture are assumed to be different from western countries.

- The main limitation of this study is its crosssectional design so that the direction of causal relationship cannot be drawn.

model, ${ }^{3}$ the organisational justice model $^{4}$ and the workplace social context. ${ }^{5}$

The idea of social context and health was originally generated from studies which examined a neighbourhood context, a number of which revealed that residential environment, socioeconomic characteristics and social structures influence people's health. ${ }^{6}$ In particular, social capital in neighbourhoods is an 
important domain of social context in neighbourhood studies. Social capital refers to features of social organisation, which, by facilitating coordinated actions, are able to improve societal efficiency, including trust, norms and networks. ${ }^{7}$ It is well recognised that social capital is associated with a variety of health outcomes, such as smoking behaviours, ${ }^{8}{ }^{9}$ obesity, ${ }^{10}$ hypertension, ${ }^{11}{ }^{12}$ self-rated health ${ }^{1314}$ and mental health. ${ }^{15} 16$

The idea of social capital theory is a natural candidate for expansion to occupational settings. Kawachi ${ }^{17}$ argued that social capital is likely to arise at any place where people spend a significant amount of their time. ${ }^{5}$ The workplace represents an important social unit, particularly given that many people spend the majority of their waking hours at work and that the workplace is a significant source of social relations. ${ }^{18}$ Some studies have recently examined workplace social capital and health. ${ }^{5}$ 18-25 The Finnish Public Sector Study group reported the effect of workplace social capital on health, including smoking behaviour, ${ }^{26}$ self-rated health, ${ }^{18}$ depression, ${ }^{19}$ mortality ${ }^{23}$ and hypertension. ${ }^{21}$

While an association between social capital and hypertension has been suggested by studies in a neighbourhood context, ${ }^{27}$ only a study from the Finnish Public Sector Study reported their association in an occupational setting. ${ }^{21}$ We therefore considered that it would be interesting to determine the association between workplace social capital and systolic blood pressure (SBP) among the Japanese working population since working behaviour and culture are assumed to be different from western countries.

Here, we examined the association between workplace social capital at the workplace level and SBP with consideration to individual factors based on the job-demandcontrol model.

\section{METHODS}

The study was conducted under a cross-sectional design at a diversified Japanese conglomerate which manufactures innovative products based on chemical and material sciences and employs approximately 25000 workers throughout Japan. The individuals of this study were 5844 workers who belonged to group companies at $\mathrm{X}$ City (population129 000). We used data obtained at annual health examinations, the provision of which is mandatory for employers in Japan. Of the 5844 workers, 5368 (92\%, 3711 men and 1597 women) were entered into the study. The individuals who received drugs for hypertension $(\mathrm{n}=531)$ and who lacked information on any variable $(n=167)$ were excluded from the analyses, leaving 4735 individuals (3281 men and 1454 women) for inclusion.

The individuals were informed by printed material which noticed that data of health check-up would be used for research purpose with anonymity. These procedures were formally confirmed by the company and the labour union. We reported the results of the study to the managers of the company, and a submission to a journal was also formally authorised by the company. The study was approved by the Ethics Committee for Medical Care and Research at the University of Occupational and Environmental Health, Japan.

\section{Measurements}

An annual health examination was operated by the occupational healthcare centre owned by this company group. The annual health examination data included SBP, body weight, height and self-reported medical history and lifestyle factors such as smoking, habitual alcohol drinking, walking ( $1 \mathrm{~h}$ or more per day) and exercise (30 min or more two or more times per week). SBP and diastolic blood pressures (DBP) were measured by trained occupational public health nurses using a standard automated sphygmomanometer in a seated posture, with high BP individuals being given two tests to avoid white-coat hypertension (with the lower values being recorded).

Employment grade according to the administrative data was also used: workers who were originally employed at the headquarters, or workers who were locally hired by affiliate companies.

\section{Job stress and social support}

We used the Brief Job Stress Questionnaire to measure quantitative workload, qualitative job overload, physical demand, job control, interpersonal conflict, supervisor support and coworker support, using the demandcontrol-support model. ${ }^{28}$ The Brief Job Stress Questionnaire is a validated self-assessment scale which measures job-stressors based on the demand-controlsupport model and has been widely used in Japanese occupational settings. ${ }^{29-35}$

Quantitative workload was measured with a three-item scale consisting of the items 'working hard', 'amount of work' and 'insufficient time to complete work', with a four-point response scale (from 'strongly disagree' $=1$ to 'strongly agree' $=4$. Qualitative job overload was measured with a three-item scale which consisted of the items 'requires concentration', 'complex job which requires a high level of knowledge and skills' and 'requires constant thinking about the job during work hours', with the same response scale. Physical demand was measured with a single-item scale consisting of the item 'physically hard work', with the same response scale. Job control was measured with a three-item scale consisting of the items 'work at own pace', 'make decisions at work' and 'influence over worksite policy', with the same response scale.

Interpersonal conflict was measured with a three-item scale consisting of the items 'interpersonal conflict within a workgroup', 'conflict with other workgroups' and 'friendly atmosphere in a workgroup', with the same response scale. Total scores for quantitative workload, qualitative job overload, job control and interpersonal conflict ranged from 3 to 12 , with a higher score 
indicating a greater degree of job demand, job control and interpersonal conflict.

Supervisor support and coworker support were assessed using three-item, four-point Likert-type scales. Each scale consisted of items on (1) the extent to which a respondent felt at ease when talking with supervisors/ coworkers, (2) the extent to which supervisors/coworkers were relied on when work difficulties were encountered and (3) the extent to which supervisors/coworkers were willing to listen to a respondent's personal problems, with a four-point response scale from 'strongly disagree' $=1$ to 'strongly agree' $=4$. Total scores ranged from 3 to 12, with a higher score indicating greater support from supervisors/coworkers.

These scales showed acceptable reliability levels of internal consistency in this study, with Cronbach's $\alpha$ score of 0.80 for quantitative workload, 0.73 for qualitative job overload, 0.72 for job control, 0.64 for interpersonal conflict, 0.85 for supervisor support and 0.82 for coworker support.

We also used a different measure of social capital using the above questions. People who responded with 'strongly disagree' to questions (1), (2) and (3) above were coded as having a lack of conversable sense, trust and helpfulness with supervisors and with coworkers.

\section{Measurements of social capital at the workplace level}

According to the major line of research on social capital, social capital consists of structural, cognitive and relational components. ${ }^{36}$ In the present study, we attempted to assess relational workplace social capital, which mainly refers to the trust, associability, interpersonal obligations and expectations among organisations. Indicators of social capital, aggregated to the workplace level, were obtained from the Brief Job Stress Questionnaire. We used two different measures of social capital at the workplace level for analysis. First, group means of supervisor support and coworker support by workplace were used for measurement of the workplace level of supervisor support and coworker support. Second, proportions of a lack of conversable sense, trust and helpfulness with supervisors and with coworkers at each workplace were used as a second measure of social capital at the workplace level.

Fifty-eight workplaces were defined as being small affiliate companies or factory sites.

\section{Statistical analyses}

The contextual effect of workplace social capital on SBP was examined using a multilevel regression analysis with a random intercept. The model included both individuallevel and workplace-level factors. Individual-level factors consisted of sex, age, employment grade, body mass index (BMI), walking, exercise, number of cigarettes per day, quantitative workload, qualitative job overload, physical demand, job control, interpersonal conflict, supervisor support and coworker support. Group means of supervisor and coworker supports were entered as workplace-level factors. The model applied the centring approach in which individual levels of supervisor support and coworker support were centred by subtracting the group means. Categorical variables were coded as follows: alcohol drinking (rarely drink as 0 , occasionally drink as 1 , drink almost every day with ethanol at $1-22 \mathrm{~g} /$ day as $2,23-45 \mathrm{~g} /$ day as $3,46-68 \mathrm{~g} /$ day as 4 and $\geq 69 \mathrm{~g} /$ day as 5), walking (less than $1 \mathrm{~h}$ a day as $0,1 \mathrm{~h}$ or more a day as 1 ), exercise (30 min or more at two or more times per week as 1 , less than this as 0 ). We further analysed other models in which a lack of conversable sense, trust and helpfulness with supervisors and with coworkers at an individual level and their proportion were used as workplace level.

These analyses were thoroughly expanded from a model which included only age and sex to those including individual and workplace contextual factors. Specifically, model 1 included sex (if applicable), age and the alternative of contextual factors at the workplace level. Model 2, like model 1, additionally adjusted for employment status, shift work, hours of overtime in a previous month, BMI, walking, exercise, number of cigarettes per day and alcohol drinking. Model 3 further included quantitative workload, qualitative job overload, physical demand, job control, interpersonal conflict and a lack of conversable sense, trust and helpfulness at the individual level. We also examined significance of interaction between sex and workplace social capital measures, and the analyses were stratified by sex when significant interactions were observed. All statistical analyses were performed using STATA release V.12 (Stata, College Station, Texas, USA).

\section{RESULTS}

Individuals characteristics and prevalence of hypertension, as well as the means of SBP, are shown in table 1. Table 2 shows characteristics according to workplace.

Coworker support at the workplace level was associated with decreased SBP (coefficient $=-1.97 \mathrm{~mm} \mathrm{Hg}, \mathrm{p}=0.043$ ) in the age-sex adjusted model (table 3). This association was weakened after adjustment for individual-level factors. The sex-stratified analyses on coworker support were also conducted since the interaction of sex and coworker support had shown marginal significance $(p=0.066)$. In women, higher coworker support at the workplace level was associated with a decreased SBP, which was not substantially changed by adjustment of individual job stressrelated factors (coefficient $=-4.76 \mathrm{~mm} \mathrm{Hg}, \mathrm{p}=0.007$ in model 1 , coefficient $=-3.74 \mathrm{~mm} \mathrm{Hg}, \mathrm{p}=0.024$ in model 2, and coefficient $=-3.68 \mathrm{~mm} \mathrm{Hg}, \mathrm{p}=0.032$ in the fully adjusted model). In contrast, coworker support showed no association with SBP in men. Table 4 shows the associations between a lack of conversable sense, trust and helpfulness at the workplace level and SBP. A lack of trust in coworkers at the workplace level was positively associated with SBP in all individuals (coefficient $=0.26 \mathrm{~mm} \mathrm{Hg}$, $\mathrm{p}=0.047$ in model 1), and in all models among women (coefficient $=0.69, \mathrm{p}=0.001$ in model 1 , 
Table 1 Individuals characteristics by blood pressure and prevalence of hypertension

\begin{tabular}{|c|c|c|c|c|c|c|c|c|c|}
\hline & \multicolumn{3}{|c|}{ Total $(n=4735)$} & \multicolumn{3}{|c|}{ Men $(n=3281)$} & \multicolumn{3}{|c|}{ Women $(n=1454)$} \\
\hline & Per cent & Mean & SD & Per cent & Mean & SD & Per cent & Mean & SD \\
\hline \multicolumn{10}{|l|}{ Sex } \\
\hline Men & 69.3 & & & & & & & & \\
\hline Women & 30.7 & & & & & & & & \\
\hline Age & & 42.6 & 11.8 & & 42.1 & 11.9 & & 43.7 & 11.7 \\
\hline Body mass index & & 22.9 & 3.5 & & 23.4 & 3.4 & & 22.0 & 3.5 \\
\hline Systolic blood pressure & & 120.4 & 15.5 & & 122.5 & 14.7 & & 115.6 & 16.2 \\
\hline Diastolic blood pressure & & 72.6 & 11.5 & & 74.3 & 11.3 & & 68.8 & 10.9 \\
\hline \multicolumn{10}{|l|}{ Alcohol drinking } \\
\hline Rarely drink & 34.8 & & & 24.7 & & & 58.9 & & \\
\hline Occasionally drink & 34.8 & & & 35.9 & & & 32.2 & & \\
\hline Drink almost every day & 30.4 & & & 39.5 & & & 9.0 & & \\
\hline \multicolumn{10}{|l|}{ Number of cigarettes per day } \\
\hline 0 (non-smoker) & 66.6 & & & 58.5 & & & 85.8 & & \\
\hline $1-20$ & 29.9 & & & 36.7 & & & 14.0 & & \\
\hline$\geq 21$ & 3.5 & & & 4.8 & & & 0.3 & & \\
\hline \multicolumn{10}{|l|}{ Walking } \\
\hline$<1$ h a day & 66.4 & & & 60.7 & & & 79.8 & & \\
\hline$\geq 1 \mathrm{~h}$ a day & 33.6 & & & 39.3 & & & 20.2 & & \\
\hline \multicolumn{10}{|c|}{ Exercise (30 min or more two or more times per week) } \\
\hline Yes & 30.4 & & & 35.8 & & & 17.6 & & \\
\hline Engagement in shift work & 33.6 & & & 40.2 & & & 17.8 & & \\
\hline \multicolumn{10}{|l|}{ Hours of overtime work in a previous month } \\
\hline None & 28.7 & & & 18.9 & & & 51.9 & & \\
\hline$<40$ & 65.6 & & & 73.6 & & & 47.5 & & \\
\hline $40-79$ & 5.2 & & & 6.9 & & & 0.6 & & \\
\hline$\geq 80$ & 0.5 & & & 0.6 & & & 0.1 & & \\
\hline A lack of conversable sense with supervisor & 9.5 & & & 6.6 & & & 16.3 & & \\
\hline A lack of trust in supervisor & 11.5 & & & 8.3 & & & 19.2 & & \\
\hline A lack of helpfulness from supervisor & 12.5 & & & 8.7 & & & 21.4 & & \\
\hline A lack of conversable sense with coworker & 1.3 & & & 0.9 & & & 2.3 & & \\
\hline A lack of trust in coworker & 4.5 & & & 3.8 & & & 6.1 & & \\
\hline A lack of helpfulness from coworker & 5.4 & & & 4.7 & & & 7.0 & & \\
\hline
\end{tabular}

coefficient $=0.63 \mathrm{~mm} \mathrm{Hg}, \quad \mathrm{p}=0.002$ in model 2 and coefficient $=0.59 \mathrm{~mm} \mathrm{Hg}, \mathrm{p}=0.004$ in model 3). Interaction of sex and a lack of trust in coworkers was significant $(\mathrm{p}=0.002)$. A lack of helpfulness from coworkers was also associated with SBP in all individuals, with coefficients of $0.27 \mathrm{~mm} \mathrm{Hg} \quad(p=0.003) \quad$ in model $1,0.23 \mathrm{~mm} \mathrm{Hg}$ $(\mathrm{p}=0.006)$ in model 2 and $0.22 \mathrm{~mm} \mathrm{Hg}(\mathrm{p}=0.008)$ in model 3. Interaction of sex and a lack of helpfulness from coworkers was significant $(p=0.004$. $)$ Accordingly, sexstratified analyses revealed that this effect was only seen in women, with coefficients of $0.45 \mathrm{~mm} \mathrm{Hg}(\mathrm{p}=0.001)$ in model $1,0.42 \mathrm{~mm} \mathrm{Hg}(\mathrm{p}=0.001)$ in model 2 and $0.40 \mathrm{~mm} \mathrm{Hg}(\mathrm{p}=0.001)$ in model 3 .

We showed the presence of workplace-level variance in random effects from multilevel models (table 5). The models were selected from an analysis of when the workplace-level factors showed statistical significance. With regard to group means for coworker support, workplace-level variance of the null model was 13.3, while that of the model which included only coworker support at the workplace level was 11.5. This implies that $14 \%$ of workplace-level variance was explained by coworker support at the workplace level. Similarly, $9 \%$ of workplace-level variation was attributable to a lack of helpfulness from coworkers at the workplace level in both sexes.

We also examined the likelihood of association between workplace social capital and DBP and found there to be none(data not shown). Only a lack of trust in coworkers showed a marginal significance level (coefficient 0.23, $\mathrm{p}=0.082$ ).

\section{DISCUSSION}

The present study found that coworker support had a contextual effect at the workplace level and that a lack of trust in coworkers and lack of helpfulness from coworkers were associated with SBP. Sex-stratified analyses showed that these effects were only seen among women.

Our results suggest that coworkers are more important in building workplace social capital than supervisors. Evidence for this comes from our findings that measurement of coworker social capital, such as coworker support, lack of trust in coworkers and lack of 
Table 2 Workplace characteristics and social capital measures at the workplace level $(n=58)$

\begin{tabular}{|c|c|c|c|}
\hline & $\%$ & Mean & SD \\
\hline \multicolumn{4}{|l|}{ Number of employees } \\
\hline$<50$ & 50 & & \\
\hline 50-99 & 21 & & \\
\hline $100-199$ & 14 & & \\
\hline 200-299 & 8 & & \\
\hline$\geq 300$ & 7 & & \\
\hline \multicolumn{4}{|l|}{ Group means by workplace } \\
\hline Supervisor support & & 7.5 & 0.9 \\
\hline Coworker support & & 8.0 & 0.7 \\
\hline \multicolumn{4}{|l|}{ Proportions by workplace } \\
\hline A lack of conversable sense with & & 6.4 & 6.1 \\
\hline \multicolumn{4}{|l|}{ supervisor } \\
\hline A lack of trust in supervisor & & 8.5 & 8.8 \\
\hline A lack of helpfulness from supervisor & & 9.9 & 13.9 \\
\hline A lack of conversable sense with & & 5.1 & 7.4 \\
\hline \multicolumn{4}{|l|}{ coworker } \\
\hline A lack of trust in coworker & & 1.9 & 6.7 \\
\hline A lack of helpfulness from coworker & & 7.7 & 13.8 \\
\hline
\end{tabular}

helpfulness from coworkers at the workplace level, was significantly associated with SBP, whereas no association was seen for these variables with supervisors. The concept of social capital is considered to include horizontal and vertical dimensions. ${ }^{37}$ The horizontal dimension refers to the dimension across individuals at the same hierarchical level while the vertical dimension refers to that among individuals in different positions of power. In this respect, the present findings suggest that workplace social capital emphasises the horizontal rather than vertical dimension. Very few studies have actually examined the different dimensions of social capital at the workplace separately, and their results are inconsistent: one reported that the vertical dimension was associated with self-rated health while the horizontal dimension was not, ${ }^{38}$ whereas another that focused on the modifying effect of social capital reported that trust in managers. In other words, the vertical dimension of social capital modified the effects of job stress on smoking, whereas trust in coworkers did not. ${ }^{5}$ A third study reported that support from coworkers, namely the horizontal dimension, was associated with poor self-rated health. ${ }^{37}$

The present study found that the association between social capital and blood pressure was seen only in women. Although the reason for this is not clear, several possibilities can be suggested. First, in the Japanese business context, it is reasonable to assume that men are more likely to engage in work than women, and that men's attitudes are more likely than women's to be competitive towards others. On this basis, high coworker support may force men to more strongly commit themselves to work, which may mitigate the benefit of coworker support in terms of stress. Second, the so-called enkai effect ${ }^{39}$ may reduce the health benefit

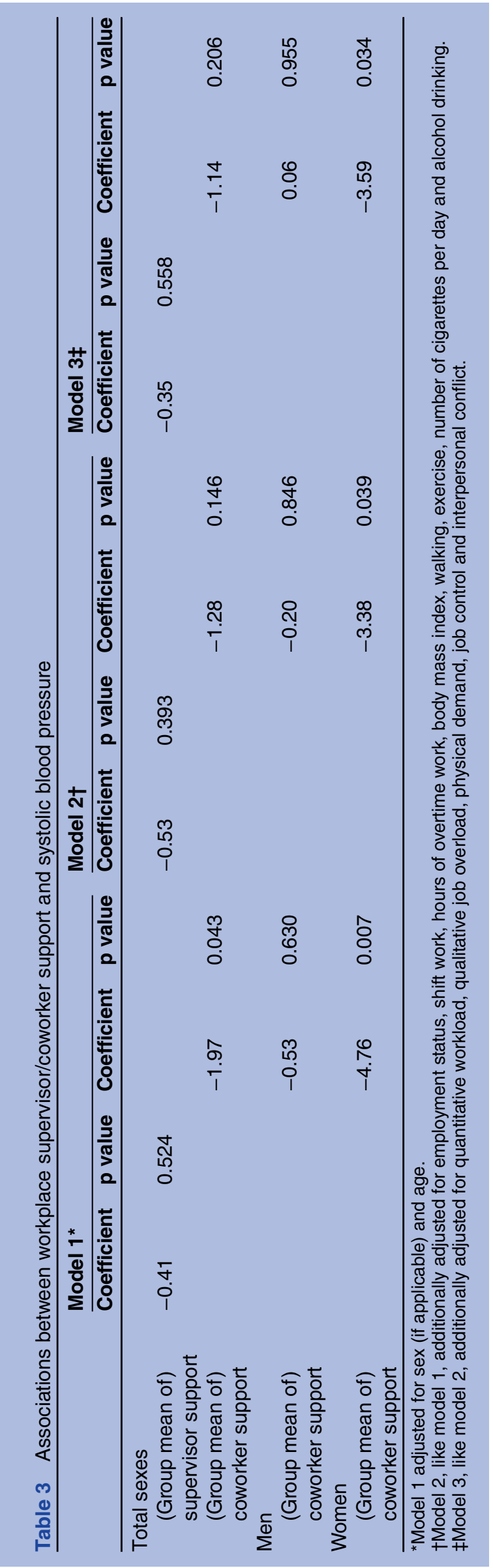


Table 4 Associations between lack of conversable sense, trust and helpfulness at the workplace level and systolic blood pressure

\begin{tabular}{|c|c|c|c|c|c|c|}
\hline \multirow[b]{2}{*}{$\begin{array}{l}\text { Measures of social capital at the workplace level* } \\
\text { Total sexes }\end{array}$} & \multicolumn{2}{|l|}{ Model 1† } & \multicolumn{2}{|l|}{ Model 2‡ } & \multicolumn{2}{|l|}{ Model $3 \S$} \\
\hline & Coefficient & p value & Coefficient & $\bar{p}$ value & Coefficient & $\overline{p \text { value }}$ \\
\hline A lack of conversable sense with supervisor & -0.02 & 0.765 & -0.02 & 0.795 & -0.02 & 0.760 \\
\hline A lack of trust in supervisor & 0.07 & 0.247 & 0.08 & 0.161 & 0.07 & 0.195 \\
\hline A lack of helpfulness from supervisor & 0.10 & 0.111 & 0.11 & 0.040 & 0.11 & 0.048 \\
\hline A lack of conversable sense with coworker & 0.30 & 0.146 & 0.27 & 0.152 & 0.27 & 0.157 \\
\hline A lack of trust in coworker & 0.26 & 0.047 & 0.23 & 0.046 & 0.22 & 0.061 \\
\hline A lack of helpfulness from coworker & 0.27 & 0.003 & 0.24 & 0.003 & 0.24 & 0.004 \\
\hline \multicolumn{7}{|l|}{ Men } \\
\hline A lack of trust in coworker & -0.01 & 0.959 & -0.03 & 0.810 & -0.04 & 0.775 \\
\hline A lack of helpfulness from coworker & 0.06 & 0.601 & 0.02 & 0.873 & 0.03 & 0.807 \\
\hline \multicolumn{7}{|l|}{ Non-habitual drinker } \\
\hline A lack of trust in coworker & 0.49 & 0.069 & 0.41 & 0.117 & 0.42 & 0.102 \\
\hline A lack of helpfulness from coworker & 0.34 & 0.096 & 0.32 & 0.103 & 0.35 & 0.064 \\
\hline \multicolumn{7}{|l|}{ Habitual drinker } \\
\hline A lack of trust in coworker & -0.10 & 0.531 & -0.07 & 0.639 & -0.09 & 0.545 \\
\hline A lack of helpfulness from coworker & 0.00 & 0.977 & -0.01 & 0.951 & -0.03 & 0.790 \\
\hline \multicolumn{7}{|l|}{ Women } \\
\hline A lack of trust in coworker & 0.69 & 0.001 & 0.63 & 0.001 & 0.61 & 0.002 \\
\hline A lack of helpfulness from coworker & 0.45 & 0.001 & 0.44 & 0.001 & 0.43 & 0.001 \\
\hline
\end{tabular}

*Proportions of a lack of conversable sense, trust and helpfulness with supervisors and those with coworkers at each workplace were used as a measure of social capital at the workplace level.

†Model 1 adjusted for sex (if applicable) and age.

†Model 2, like model 1, additionally adjusted for employment status, shift work, hours of overtime work, body mass index, walking, exercise, number of cigarettes per day and alcohol drinking.

§Model 3, like model 2, additionally adjusted for quantitative workload, qualitative job overload, physical demand, job control and interpersonal conflict.

of coworker support. 'Enkai' refers to the many informal socialising opportunities that are available to Japanese men and are held after work. It aims to strengthen social cohesion in the same workplace. Ikeda et $a \hat{l}^{9}$ reported that Japanese men with higher social support engaged in heavier drinking and a higher fat intake pattern, which could lead to increased blood pressure though overweight. This is backed up by the fact that a lack of trust in coworkers and a lack of helpfulness from coworkers were marginally associated with SBP when analyses were limited to non- drinking men (coefficient $=0.43 \mathrm{~mm} \mathrm{Hg} p=0.096$, coefficient $=0.37 \mathrm{~mm} \mathrm{Hg}, \mathrm{p}=0.058$, in model 3 , respectively). In addition, habitual drinking men perceived higher social support from supervisors and coworkers than nonhabitual drinking men in the present study. Scores of perceived individual support from supervisors were 7.5 from supervisors in habitual drinking men versus 7.2 in nonhabitual drinking men ( $\mathrm{p}$ value derived from $\mathrm{t}$ test was 0.004 ), whereas scores of support from coworkers were 8.1 in habitual drinking men versus 7.9 in non-habitual

Table 5 Workplace-level variance and SE of random effects in the multilevel models, selected from tables 3 and 4

\begin{tabular}{|c|c|c|c|c|c|c|c|c|}
\hline & \multicolumn{2}{|c|}{ Null model } & \multicolumn{3}{|l|}{ Model 0* } & \multicolumn{3}{|l|}{ Model 3† } \\
\hline & Variance & SE & Variance & SE & $\begin{array}{l}\text { Percentage of } \\
\text { reduction of variance } \\
\text { from the null mode }\end{array}$ & Variance & SE & $\begin{array}{l}\text { Percentage reduction } \\
\text { of variance from the } \\
\text { null mode }\end{array}$ \\
\hline $\begin{array}{l}\text { (Group mean of) } \\
\text { coworker support } \\
\text { (total sexes, table 3) }\end{array}$ & 13.3 & 3.6 & 11.5 & 3.3 & 14 & 3.5 & 1.2 & 73 \\
\hline $\begin{array}{l}\text { A lack of helpfulness } \\
\text { from coworker (total } \\
\text { sexes, table 4) }\end{array}$ & 13.3 & 3.6 & 12.1 & 3.3 & 9 & 3.1 & 1.1 & 76 \\
\hline
\end{tabular}


drinking men ( $p$ value derived from t test was 0.035). These results suggest that workplace social capital is also important to men, but they may be compensated by unhealthy drinking behaviours. Third, individual factors such as age, BMI and alcohol drinking, which are established risk factors for hypertension, have a stronger effect in men than women. Although we adjusted for these factors in the model, their putative confounding effects might not have been fully excluded.

Regarding the sex difference, the Finnish study ${ }^{21}$ reported that men had a lower level of workplace social capital than women, and the association between social capital and hypertension was only seen in men, which is inconsistent with our results. It argued that the reason for this is that women are more likely to be part of the social network. ${ }^{21}$ In the present study, however, men had higher social capital than women. This inconsistency is plausible because sex differences in working behaviours and cultures vary between countries and occupations.

In terms of occupational health policy, the present study may provide suitable evidence to encourage workplace-level improvement activities. Although the importance of individual-level stressors based on the job-demand-control model to the management of worker's health is clearly recognised, interventions aimed at the individual's specific stressors, such as interpersonal conflicts between particular persons, are difficult. Instead, intervention at the workplace level offers a more reasonable approach which is expected to buffer the individual's stressors. According to the population strategy theory, the present study suggests that every worker (women) in a workplace with higher social capital may receive a beneficial effect on health, although the effect size of workplace social capital was small, namely $4 \mathrm{~mm} \mathrm{Hg}$ decrease in SBP per one point increase in workplace coworker support. Several limitations of this study should be mentioned. First, the study was conducted under a cross-sectional design, which hampers any assignment of the temporal direction of causality. Second, the generalisability of the present results is uncertain because social capital is an inherent characteristic of the population, social norms and culture. The present study recruited individuals from a particular Japanese company group, and workplace culture may differ between companies and areas. Third, residual confounding of the association between workplace social capital and blood pressure may have occurred. Although we adjusted for selected factors that potentially related to blood pressure, the possible influence of other risk factors, lifestyles and psychosocial factors might still remain. In particular, the present study did not ascertain social capital outside of the workplace, although social capital in the community in which the individual lives is also an important determinant of worker health. Further, the present study lacks information on education and income, which is considered to be associated with hypertension. The present study took account of employment status, however, which explicitly reflects the individual's income and educational levels. The workers who were employed at headquarters were more likely to have higher education and income since the wage system there is markedly different from that of the workers who were locally hired by affiliate companies. Fourth, the accuracy of measuring SBP is somewhat uncertain, since health check-up is often conducted after, before and during work. Therefore, workers' conditions and behaviours such as sleep condition, smoking, commute-related exercise and workload just before check-up may affect measurements.

In conclusion, the present study revealed that social capital at the workplace level was associated with SBP and hypertension. The study also emphasises that social capital among coworkers, the horizontal dimension, are more important with respect to blood pressure than those among supervisors, the vertical dimension, in occupational settings. In addition, women are more likely to be susceptible to workplace social capital than men with regard to SBP and hypertension.

\section{Author affiliations}

${ }^{1}$ Department of Preventive Medicine and Community Health, University of Occupational and Environmental Health, Kitakyushu, Japan

${ }^{2}$ Department of Health Care Center, Asahi Kasei Corporation Nobeoka Office, Nobeoka, Japan

${ }^{3}$ Department of Health Care Center, Asahi Kasei Chemicals Mizushima Works, Okayama, Japan

${ }^{4}$ Corporate Environmental Safety Health and Quality Assurance, Asahi Kasei Corporation, Tokyo, Japan

Contributors YF and TK designed the study and directed its implementation, analysed the data and mainly wrote the draft. MK, HT, TT, KK and TK helped to collect the data and to conduct the literature review. 10 helped to supervise the field activities and designed the study's analytic strategy. All authors read and approved the final manuscript.

Funding This research received no specific grant from any funding agency in the public, commercial or not-for-profit sectors.

\section{Competing interests None.}

Ethics approval The Ethics Committee for Medical Care and Research at the University of Occupational and Environmental Health, Japan.

Provenance and peer review Not commissioned; externally peer reviewed Data sharing statement No additional data are available.

\section{REFERENCES}

1. Karasek RA Jr. Job demands, job decision latitude, and mental strain: implications for job redesign. Adm Sci Q 1979:285-308.

2. Dollard MF, Winefield $\mathrm{AH}$. A test of the demand-control/support model of work stress in correctional officers. J Occup Health Psychol 1998;3:243-64.

3. Siegrist J. Effort-reward imbalance at work and cardiovascular diseases. Int J Occup Med Environ Health 2010;23:279-85.

4. Elovainio M, Kivimaki M, Vahtera J. Organizational justice: evidence of a new psychosocial predictor of health. Am J Public Health 2002;92:105-8.

5. Sapp AL, Kawachi I, Sorensen G, et al. Does workplace social capital buffer the effects of job stress? A cross-sectional, multilevel analysis of cigarette smoking among U.S. manufacturing workers. J Occup Environ Med/Am Coll Occup Environ Med 2010;52:740-50.

6. Berkman LF, Kawachi lo. Social epidemiology. New York: Oxford University Press, 2000.

7. Putnam RD. Bowling alone : the collapse and revival of American community. New York: Simon \& Schuster, 2000. 
8. Giordano GN, Lindstrom M. The impact of social capital on changes in smoking behaviour: a longitudinal cohort study. Eur J Public Health 2011;21:347-54.

9. Sapag JC, Poblete FC, Eicher C, et al. Tobacco smoking in urban neighborhoods: exploring social capital as a protective factor in Santiago, Chile. Nicotine Tob Res 2010;12:927-36.

10. Holtgrave DR, Crosby R. Is social capital a protective factor against obesity and diabetes? Findings from an exploratory study. Ann Epidemiol 2006;16:406-8.

11. Hamano T, Fujisawa $Y$, Yamasaki M, et al. Contributions of social context to blood pressure: findings from a multilevel analysis of social capital and systolic blood pressure. Am J Hypertens 2011;24:643-6.

12. Bell CN, Thorpe RJ Jr, Laveist TA. Race/ethnicity and hypertension: the role of social support. Am J Hypertens 2010;23:534-40.

13. Kawachi I, Kennedy BP, Glass R. Social capital and self-rated health: a contextual analysis. Am J Public Health 1999;89:1187-93.

14. Kim D, Subramanian SV, Kawachi I. Bonding versus bridging social capital and their associations with self rated health: a multilevel analysis of 40 US communities. J Epidemiol Community Health 2006;60:116-22.

15. Kawachi I, Berkman LF. Social ties and mental health. $J$ Urban Health 2001;78:458-67.

16. McKenzie K, Whitley R, Weich S. Social capital and mental health Br J Psychiatry 2002;181:280-3.

17. Kawachi I. Social capital and community effects on population and individual health. Ann N Y Acad Sci 1999;896:120-30.

18. Oksanen T, Kouvonen A, Kivimaki M, et al. Social capital at work as a predictor of employee health: multilevel evidence from work units in Finland. Soc Sci Med 2008;66:637-49.

19. Kouvonen A, Oksanen T, Vahtera J, et al. Low workplace social capital as a predictor of depression: the Finnish Public Sector Study. Am J Epidemiol 2008;167:1143-51.

20. Kouvonen A, Oksanen T, Vahtera J, et al. Work-place social capital and smoking cessation: the Finnish Public Sector Study. Addiction 2008;103:1857-65

21. Oksanen T, Kawachi I, Jokela M, et al. Workplace social capital and risk of chronic and severe hypertension: a cohort study. J Hypertens 2012;30:1129-36.

22. Oksanen T, Kawachi I, Kouvonen A, et al. Workplace social capital and adherence to antihypertensive medication: a cohort study. PLoS ONE 2011;6:e24732.

23. Oksanen T, Kivimaki M, Kawachi I, et al. Workplace social capital and all-cause mortality: a prospective cohort study of 28,043 public-sector employees in Finland. Am J Public Health 2011;101:1742-8.

24. Suzuki E, Fujiwara T, Takao S, et al. Multi-level, cross-sectional study of workplace social capital and smoking among Japanese employees. BMC Public Health 2010;10:489.
25. Suzuki E, Takao S, Subramanian SV, et al. Does low workplace social capital have detrimental effect on workers' health? Soc Sci Med 2010;70:1367-72.

26. Kouvonen A, Vahtera J, Vaananen A, et al. Relationship between job strain and smoking cessation: the Finnish Public Sector Study. Tob Control 2009;18:108-14.

27. Hamano T, Fujisawa $Y$, Ishida $Y$, et al. Social capital and mental health in Japan: a multilevel analysis. PLOS ONE 2010;5 e13214.

28. Shimomitsu T, Hratani T, Nakamura K, et al. The final development of the Brief Job Stress Quesionaire mainly used for assessment of the individuals. In: Kato M, ed. The Ministry of Labour sponsored grand for the prevention of work-related illness: the 1999 report. Tokyo: Tokyo Medical College, 2000:126-64.

29. Takaya M, Hasegawa Y. An analysis of the relation between stress coping profile and job stress using structural equation modeling (SEM). Sangyo Eiseigaku Zasshi 2010;52:209-15.

30. Tahara H, Yamada T, Nagafuchi K, et al. Development of a work improvement checklist for occupational mental health focused on requests from workers. J Occup Health 2009;51:340-8.

31. Sato $Y$, Miyake H, Theriault G. Overtime work and stress response in a group of Japanese workers. Occup Med (Lond) 2009:59:14-19.

32. Kobayashi $\mathrm{Y}$, Kaneyoshi A, Yokota A, et al. Effects of a worker participatory program for improving work environments on job stressors and mental health among workers: a controlled trial. $J$ Occup Health 2008;50:455-70.

33. Kawano Y. Association of job-related stress factors with psychological and somatic symptoms among Japanese hospital nurses: effect of departmental environment in acute care hospitals. J Occup Health 2008;50:79-85.

34. Kawakami N, Takao S, Kobayashi Y, et al. Effects of web-based supervisor training on job stressors and psychological distress among workers: a workplace-based randomized controlled trial. J Occup Health 2006;48:28-34.

35. Harada H, Suwazono Y, Sakata K, et al. Three-shift system increases job-related stress in Japanese workers. J Occup Health 2005;47:397-404

36. Nahapiet J, Ghoshal S. Social capital, intellectual capital, and the organizational advantage. Acad Manage Rev 1998;23:242-66.

37. Liukkonen V Virtanen $\mathrm{P}$, Kivimaki M et al. Social capital in working life and the health of employees. Soc Sci Med 2004;59:2447-58

38. Chen DR, Lin YY, Chung KP. Career stress and female managers health in Taiwan's hospitals: a multilevel model approach. Health Care Manage Rev 2008;33:40-50.

39. Ikeda A, Kawachi I, Iso $\mathrm{H}$, et al. Gender difference in the association between social support and metabolic syndrome in Japan: the 'enkai' effect? J Epidemiol Community Health 2011;65:71-7. 